\title{
DIDACTIC PROBLEMS OF THE DIGITALIZATION OF EDUCATION
}

\author{
Kuznetsova A.Ya. \\ Novosibirsk State Pedagogical University, Novosibirsk,e-mail:phileducation@yandex.ru \\ The article presents the problem of the development of educational didactics as important for modern society. \\ It is pointed out that elements of modern didactics are presented in numerous works on the theory of education. At- \\ tention is paid to the current state of the main components of didactics: the content and methods of teaching. The in- \\ troduction contains a description of the state of didactics in Russia in the 17 th century. The historical steps leading to \\ the transformation of the educational system are outlined. The cultural and historical character of their improvement \\ is emphasized. Based on an analytical review of modern scientific sources, it is shown that the transition to digital \\ forms of education is accompanied by an increase in the activity of pedagogical research on learning processes in \\ Russia. New special concepts used in the description of the distance education process are listed. A description of a \\ number of information technologies that form the foundation of digital learning and upbringing processes is given \\ The need in the theory of education to update the modern paradigm of education, taking into account the digitaliza- \\ tion of didactic models, is noted. Reflection of modern digital education resources presented in scientific literature is \\ carried out. Expansion of didactic opportunities in the context of digitalization of education is noted. The conclusion \\ is made about the need to systematize the already solved problems of distance learning. New problems generated \\ by digitalization are outlined.
}

Keywords: learning process, teaching method, information technology, digital resources, digital paradigm of education, development of didactics

A cultural-historical analysis of education problems shows that the state of didactics can influence the development of the entire society. Historically, didactic methods have evolved over thousands of years. Practice, reflection and cultural translation of didactics were systematized into pedagogical theories [1]. Turyshev I.K., comprehending the history of the development of pedagogical ideas in Russia, shows how the didactics of Russian education gradually, with great efforts of a practical nature, very slowly moved through scholasticism to creative methods of teaching and thinking [2, p. 84]. In didactics of the early XX centuries. along with the experimental method, he singles out, as the fundamental, the verbal-book method of teaching. Historically, there was a gradual formation of more and more verbal and book teaching methods in terms of the level of development: The primary one is a dogmatic method, based on primitive cramming, on scholasticism. The teacher using this method does not allow the learner to comprehend the content, to convey its meaning in his own words. The main goal of the method is to memorize the text verbatim. To use the dogmatic method, the teacher focuses the student's attention on the need to have a good memory. The learning outcome depends on the possession of the verbal apparatus. Dogmatic teaching excludes the creative nature of mastering knowledge, excludes individual reflection on the content of learning by both the student and the teacher. The method of retelling the content of the text of the textbook by the teacher, its literal reproduction by the student can be attributed to a higher didactic level. Its application presupposes the presence of the rudiments of reflexivity in the activities of the teacher and the possible inclusion of the student's consciousness in the comprehension of the content of education. The method of explaining the material of the textbook by the teacher and the subsequent reproduction of it in their own words by the students raises didactics to an even higher level of verbal and book teaching. The method of explanation does not imply the student's own productive mental work, but his reflexive activity is allowed. The student can retell the content of the text in his own words, which requires comprehension of both the text and his own statement [2, p. 84].

The dogmatic method was the main one in the education system at the Kiev Theological Academy and the Moscow Slavic-GreekLatin Academy in the 17th century. Physics in these important educational institutions of Russia was taught in the subject of philosophy in Greek and then in Latin. Significant changes in Russian didactics of the 18th century, which led to the transformation of teaching methods and the liberation of the teaching system from the dominance of the dogmatic teaching method, were initiated by the activities of M.V. Lomonosov on the translation of scientific literature into Russian. It marked the beginning of fundamental changes, first in the content of education, and then led to phenomenological changes in the system of national education. In 1976 ye. Wolfian Experimental Physics [3], translated by Lomonosov from latin, was published. This is how the first textbook on experimental physics in russian appeared in Russia. In accordance with a special decree of the Senate, which instructed the translator (M.V. Lomonosov) to lecture on this subject in russian. The transition to russian in the verbal and book teaching method allowed Lomonosov to introduce 
new concepts of physics and technology: horizon, refraction of rays, atom, molecule, temperature, etc. As a result, the study of physics, the development of technical terminology became available to a wide range of students in Russia already in the 19th century. Without such changes in the content and methods of teaching, intended for all strata of society, Russia would not have had the opportunity to make the historical scientific and technological transformations of the 20th century.

Currently, in the conditions of the scientific and technical information society, the verbal and book teaching method still forms the basis of modern didactics. Along with this, the digitalization of society, education and the training system introduces significant changes in the state of the content, processes and learning outcomes.

\section{Literature review}

The modern level of intellectualization of society and education [4], the widespread use of digital distance learning forms in society, the detailing of digital presentation of information, the formation of a digital educational space, the intellectual nature of digital technologies create conditions for the formation of a distance-digital education system (DDSE). The theoretical description of the digitalized education system in modern sources contains a listing and analysis of the content of new concepts of digital didactics: digital school, digital university, open online courses; open educational resources, integrated digital educational environment - concepts that lay the foundation for a new paradigm of digital distance education. The digital school provides free access to electronic educational content; the model of a digital university is reflected in a software package that provides educational, managerial and communicative learning functions [5]. The digitalization of the education system contains the general idea of transformations, which are called the digital revolution. Adapting to the digital revolution means that the education system gets the maximum benefit from digitalization [6]. The transformations associated with the "digital revolution" contain new opportunities for further mastering the personality-oriented paradigm of education: self-development in education; activation of students' cognitive activity; taking into account the individual characteristics of students; increasing the effectiveness of training through the implementation of a student-centered learning model. Revolutionary changes involve the development of a strategy for the development of students' digital competence; integrated implementation of distance online technologies in higher education organizations; increasing opportunities in organizing students' independent work; development and mastering of digital tools for interaction between students and teachers in the educational process [7]. The practical development of digitalization can be effectively used to solve important social and educational problems: increasing the availability and quality of education. The effectiveness of digital technologies as new communication tools affects the expansion of intercultural communication, provides the opportunity to use a wider range of forms of communication in the educational multicultural space of universities [8]. In line with general transformations, universities are embarking on an independent digital transformation of curricula, using the experience of other universities and focusing on opportunities to improve the quality of education through certain solutions for the digitalization of materials and services. as a result of mastering digital didactics, digital renewal of teaching content, development and mastering of digital teaching methods, digital forms and means of education, a university can get a significant improvement in learning outcomes.

The Digital University project developed for its implementation in 2022 serves as an example of digitalization of higher education. It is important to comprehend digitalization aimed at solving the problems of didactics as a general fundamental problem of learning. The digital paradigm is becoming a full-fledged component of modern education. Currently, the use of information technology leads to the transfer of educational materials to a digital environment, to the replication of digital tools. Further immersion of education in the information environment requires a full-fledged development of all elements of didactics that ensure the modern level of quality of education. The possibilities of digital didactics should be extended to planning learning outcomes and optimizing all didactic elements: learning content, methods, means and forms of educational work, the development of digital training and education projects [9].

The rather abrupt transition of educational institutions to distance learning, accelerated by the 2020 pandemic, is associated with the introduction of digitalization of learning processes. Theoretical comprehension of these processes leads to the formation of elements of a new digital paradigm of education. The practice of working in the new digital paradigm also requires detailed reflection on all 
elements of learning. Formally, a digital learning system begins with a more arbitrary choice of place - time (coordinates) and forms of the learning process. Its organizational capabilities are expanding. Information-digital form of education allows both collective learning and the development and implementation of an individual educational path. Digital technologies enrich didactics with a set of learning forms. The teaching uses: multimedia scripts of lessons and lectures; educational video and audio materials, 3D; educational audio materials, 3D; studying programs; virtual museums, libraries and laboratories; individual control systems of progress, electronic diaries, reports, collections of tests [10]. New forms of learning, in which learners not only actively consume electronic resources, but also master the function of creators of new resources, allow deepening the subject-subject relationship [11]. Distance education poses the problem of mastering information and communication technologies for specialists in the field of education. The use of digital technologies makes it necessary to strengthen the virtual communication of specialists, strengthen the development of scientific, technical, cultural, economic ties, and form a common language of communication [12].

The educational environment of preschool education (PE) is also immersed in the general movement of digitalization. Digital technologies are being updated at the points of development of the formation of a digital educational environment for PE. The creation of a developing environment corresponding to the natural inclinations of a person, an active environment in scientific sources is attributed to the strategic tasks of modern preschool education, which fully corresponds to the classical idea of free education (Russo, Tolstoy). Digital technologies make it possible to develop alternative educational programs, taking into account the individual needs and interests of PE. It is assumed that the development of additional educational programs, as well as the improvement of the basic ones, is purposefully aimed at including children from an early age in active developmental activities in accordance with their natural data. A special place in the study is occupied by the problem of the formation of the ability for professional self-determination of children from an early age; researchers are looking for the possibility of developing the ability for social selfdetermination in young children [13].

\section{The problem and purpose of the study}

The purpose of the article is to show that the transition to digital forms of education and upbringing gives rise to numerous didactic and educational problems in the education system. Many of these problems are in the field of attention of theorists and practitioners of educational activities. The solution of practical problems of digital learning creates new didactic problems: the result of education, which is in conditions of continuous transformation, depends on the quality of solving didactic problems and continuous reflective attention to them. The digitalization of management processes combined with their reflexivity not only expands the set of management tools, but also makes it possible to fundamentally change the quality of the management system of modern education. Among the problems of the formation of a distance-digital environment of education, the following are distinguished as the main didactic problems: digital competence of a teacher; digital management of the process of education, training, upbringing; development of electronic courses; development of electronic controls; improving the quality of the educational process during the transition to digital forms of education [14].

A digital resource in models imitating professional activities is able to ensure the integration of science, technology, digital pedagogical management of the educational process based on existing uniform standards for training highly qualified personnel with professional digital literacy skills [15].

\section{Research results and discussion}

The increased attention to the problems of digital didactics is expressed both in the growth of the number of relevant theoretical studies and in the active practical development of digital technologies. Thus, at the Siberian Federal University, work was carried out that made it possible to determine the indicators of digital competence of specialists working in the field of education. Scientists have developed a digital model of competencies for an education specialist, consisting of basic and professional levels. The model was tested in the Siberian region. As a result of the attention of modern researchers to the problems of digital didactics in the practice of education, professional standards for the digital competence of a specialist have been approved. Based on the developed models, scientists were able to improve the training of masters in specialties focused on the practice of digitalization. The digitalization of education and society, the digital revolution also gives rise to new problems, certain humanitarian threats, such as information and psychological security [16]. 
Analysis of scientific literature shows that the results of digitalization are reflected in the formation of certain new digital forms of didactics. They act as elements of the digital space. digital educational process. Digitalization changes the forms of education and upbringing, the forms of contacts between people in the learning process [11], digital forms of educational information in Internet resources, etc. In the digital educational environment, already existing didactic forms are widely used: organization and control of training, various types of lectures, classical seminars and workshops, collective and individual project assignments, tests and creatively combined forms of training, including at the same time a lecture, an analytical seminar and conference forms of training. The digital environment makes it possible to organize the management of the educational process on the basis of its reflective forms: mutual control and self-control. In addition, the presence of a digital space increases the possibilities for distance learning, the use of new forms: distance educational online technologies, multimedia scripts for lectures, seminars, and lessons. The digital environment allows the wider use of video and audio materials, virtualization programs by transferring the online educational process to museums and libraries [17]. The inclusion of a student in research activities organically fits into the organization of the digital educational process. At webinars, a culture of scientific communication is formed and develops, elements of collective thinking activity are formed. The results of discussions, reports, drawn up in the form of texts, become the basis for preparing material for publication in educational and scientific publications [17]. Research activity, organized as a collective mental activity, using information technical means, most productively allows you to combine individual and collective forms of developmental educational work.

\section{Conclusions}

Theoretical work on understanding the digitalization of education leads to the formation of a new pedagogical paradigm [18]. At present, in practice and in reflexive-semantic pedagogical activity within the framework of the digital educational process, separate important constituent elements are distinguished: digital educational environment; digital forms of presentation of educational content; digital educational technologies; digital teaching methods, etc. The latter are distinguished by time savings and acceleration of the processes of working with information. Comprehension of the ongoing digitalization of education, scientific reflection of this understanding, discussion of the results of its analysis requires the development of a new one and filling the existing categorical apparatus with content that corresponds to the conditions of the digital environment. The quality of this methodological activity will affect the success of the formation of the digital education paradigm. Of particular importance for improving the modern educational paradigm are the concepts of the digital information space and the digital educational environment, which become a means of educational activity. For four centuries, the generally accepted verbal and book teaching methods have gone from dogmatic, aimed exclusively at developing the individual's memory, to a productive, creative teaching method. Modern teaching theory includes the methodology and reflection of teaching didactics aimed at the formation of productive thinking.

Many digital methodological forms have already been developed and are ready for use. Further updating of the digital educational environment requires not only their systematization, but also the reflexivity of teachers. The digitalization of educational processes requires a revision and rethinking of the practice of education, ranging from the didactic steps of individual teachers to numerous educational programs of training systems. Currently, the problem of developing productive digital teaching methods that correspond to the creative nature of the students' development is being actualized. Without reflexive consideration of the productivity of the new digital method, it becomes possible to return didactics to the level of dogmatic teaching. The reproductive method of teaching creates conditions for enriching the student with a significant amount of information that is not intended for his personal development. The transition from a book to a digital form of education requires continuous professional pedagogical work to adapt the existing classical didactics to a new digital form of education, provided that the creative nature of learning is ensured. The creation of a project for a digital educational space and reflexive work with its content becomes an additional function of the pedagogical sphere of education.

\section{References}

1. Kuznetsova A.Ya. Reflexive mechanisms of modern educational activity. European Journal of Natural History. 2020. no. 3. P. 60-64. DOI: 10.17513/ejnh.34087.

2. Turyshev I.K. The main problems of the history of the development of pre-revolutionary and Soviet methods of teaching physics. Dissertation for the degree of Doctor of Pedagogical Sciences Vladimir. 1981. 463 p. 
3. Lomonosov Mikhailo. Wolfian Experimental Physics. $\mathrm{SPb} .:$ Imperial Academy of Sciences. 1746. $193 \mathrm{p}$.

4. Kuznetsova A.Ya. Humanization of education and intelligence. Novosibirsk State Pedagogical University. Novosibirsk. 2006. $202 \mathrm{p}$.

5. Vezetiu E.V., Petrishchev I.O., Shubovich V.G., Varnavskaya O.O., Kutepov M.M. Digital technologies in the organization of the educational process in the teachers' training system. Revista de la Universidad del Zulia. 2020. vol. 11. no. 31. P. 438-448.

6. Karsenti T., Kozarenko O.M., Skakunova V.A. Digital technologies in teaching and learning foreign languages: pedagogical strategies and teachers' professional competence. Education and Self-Development. 2020. vol. 15. no. 3. P. 76-88. DOI 10.26907/esd15.3.07.

7. Limarev Pv., Limareva Yu.A., Zinovyeva E.G. Vikulina V.V., Votchel L.M., Grygoryants I.A. Distance learning online technologies as a promising form of the educational process for the humanities. Journal of Physics: Conference Series. 1st International Scientific Conference «ASEDU-2020: Advances in Science, Engineering and Digital Education». 2020. P. 012188.

8. Biryuk D.V. Application of digital educational technologies and means of intercultural communication in the multicultural educational environment of universities // Materials of the All-Russian scientific-practical conference with international participation. Resp. editor L.V. Akhmetova. 2020. P. 152-155.

9. Platonova A.Z., Olesova M.M., Storozheva N.N., Evseeva M.M. Digital technologies in educational environment. EurAsian Journal of BioSciences. 2020. vol. 14. no. 2. P. 5441-5444.

10. Malygina O.A., Goncharova N.A. Digital technologies in the educational system. Materials of the international scientific and practical conference. Ural State Mining University. Ekaterinburg, 2020. P. 638-639.

11. Rozhkova A.V. Application of digital technologies in modern educational institutions. European Proceedings of Social and Behavioural Sciences EpSBS. Krasnoyarsk Science and
Technology City Hall. Krasnoyarsk. 2020. P. 818-824. DOI: 10.1051/shsconf/ 20208700106.

12. Kabanov A., Savelieva N.Kh., Nevraeva N.Yu., Gnatyshina E.A., Pinchukova O.S. Modern digital technologies in the professionaloriented multicultural education. SHS Web of Conferences. International Scientific and Practical Conference "Teacher Professionalism: Psychological and Pedagogical Support of a Successful Career" (ICTP 2020). 2020. P. 00106.

13. Meshalkina A.N. Implementation of additional charged educational services as a condition of quality and variability of preschool education. Professional English in Use. Materials of the V All-Russian scientific-practical conference. 2019. P. $177-180$.

14. Zhestkova Ye.A., Maklaeva E.V., Filippova L.V., Fomina N.I., Fedorova S.V. Digital competence of a teacher as a means of education process managing in a high school. Advances in Social Science, Education and Humanities Research. Proceedings of the International Scientific Conference "Digitalization of Education: History, Trends and Prospects" (DETP 2020). 2020. P. 586-592. DOI: 10.2991/assehr.k.200509.107.

15. Pugacheva N., Kirillova T.V., Kirillova O.V., Luchinina A., Korolyuk I., Lunev A. Digital paradigm in educational management: the case of construction education based on emerging technologie. International Journal of Emerging Technologies in Learning. 2020. vol. 15. no. 13. P. 96-115.

16. Ermolovich E.V., Timoshkov A.V. Digital competence of mediation specialist in education. Journal of Siberian Federal University. Humanities and Social Sciences. 2020. vol. 13. no. 9. P. 1499-1509.

17. Andreev A.A. Opportunities for Massive Open Online Courses in Higher Education. E-Learning in Continuing Education. 2016. no. 1. P. 136-139.

18. Kuznetsova A. Ya. Improvement of the methodology of researching problems of education European Journal of Natural History. 2020. № 6. P. 25-29. DOI: 10.17513/ejnh.34136. 